\title{
Comunicação
}

[Communication]

\section{Freqüência de cães reagentes para Neospora caninum em São Luís, Maranhão}

[Frequency of Neospora caninum in dogs from São Luís, Maranhão]

\author{
W.C. Teixeira ${ }^{1,3}$, M.I.S. Silva ${ }^{1}$, J.G. Pereira ${ }^{1}$, A.M.. Pinheiro ${ }^{2}$, M.A.O. Almeida ${ }^{2}$, L.F.P. Gondim ${ }^{2}$ \\ ${ }^{1}$ Universidade Estadual do Maranhão \\ Caixa Postal 09 \\ 65055-970 - São Luís, MA \\ ${ }^{2}$ Escola de Medicina Veterinária - UFBA - Salvador, BA \\ ${ }^{3}$ Bolsista BIC/FACT
}

\begin{abstract}
Neospora caninum (Protozoa: Apicomplexa) é um protozoário intracelular, relatado primeiramente em cães (Bjerkås et al., 1984; Dubey et al., 1988) e posteriormente associado a aborto em bovinos (Thislsted e Dubey, 1989). Os cães são os hospedeiros definitivos (McAllister et al., 1998).
\end{abstract}

Este trabalho registra a infecção natural por $N$. caninum em cães do município de São Luís, Maranhão, por meio de estudo sorológico.

Foram colhidas amostras de sangue, por punção da veia radial, de 100 cães adultos (53 machos e 47 fêmeas), sem raça definida, capturados pelo Centro de Controle de Zoonoses em São Luís, MA. As amostras foram centrifugadas a 1500rpm, por cinco minutos para obtenção dos soros, que foram estocados em tubos tipo eppendorf e mantidos a $20^{\circ} \mathrm{C}$, até a realização do teste de imunofluorescência indireta (IFI) para detecção de anticorpos para $N$. caninum. Consideraram-se positivas as amostras reativas no ponto de corte 1:50, conforme técnica descrita por Dubey et al. (1988).

Para análise dos resultados, foi utilizado o teste do qui-quadrado.

Do total de amostras séricas, 45 foram positivas, sendo $60 \%$ de machos e $40 \%$ de fêmeas. Não houve diferença de freqüência quanto ao sexo. Basso et al. (2001), Patitucci et al. (2001), Souza et al. (2002) e Cañón-Franco et al. (2003) também não observaram diferença na soroprevalência em relação ao sexo, sugerindo que machos e fêmeas podem ser igualmente infectados.

Para a determinação de anticorpos para $N$. caninum, usou-se a técnica da IFI, empregada na maioria dos trabalhos sorológicos em cães (Björkman e Uggla, 1999). A diluição de corte 1:50 permite diferenciar os animais infectados dos não infectados. Dessa forma, os animais positivos são considerados infectados no momento da colheita das amostras.

Os títulos de anticorpos para $N$. caninum variaram de 1:50 a 1:800 (Tab. 1). Observou-se elevada freqüência de cães soropositivos $(31,1 \%)$, com título de 1:50, semelhante a resultados descritos por Trees et al. (1993) e Barber et al. (1997, o que poderia sugerir falsos positivos, atribuído a reações inespecíficas de anticorpos, principalmente com Toxoplasma gondii, que reagiria de forma cruzada. Trees et al. (1993) não evidenciaram nenhuma relação entre anticorpos anti-N. caninum e anti-T.gondii, por meio da IFI em cães infectados.

Recebido em 11 de abril de 2005

Aceito em 6 de março de 2006

Autor para correspondência (corresponding author)

E-mail: whabtyfranct@yahoo.com.br 
Tabela 1. Freqüência dos títulos de anticorpos para Neospora caninum em soros de cães, no município de São Luís, MA

\begin{tabular}{lcc}
\hline \multirow{2}{*}{ Reciproca dos títulos } & \multicolumn{2}{c}{ Soros positivos } \\
\cline { 2 - 3 } & $\mathrm{n}$ & $\%$ \\
\hline 50 & 14 & 31,11 \\
100 & 12 & 26,67 \\
200 & 13 & 28,89 \\
400 & 2 & 4,44 \\
800 & 4 & 8,89 \\
Total & 45 & 100,00 \\
\hline
\end{tabular}

De acordo com Dubey et al. (1988) e Hay et al. (1990), títulos de anticorpos IgG $\geq 1: 400$ são indicativos de quadro de neosporose clínica. Neste levantamento, foram detectados seis cães com títulos $\geq 1: 400$, sem apresentar sinais clínicos da doença.

Dados de prevalência relatados na literatura têm ampla variação desde 1\% nas Ilhas Malvinas (Barber et al., 1997) até 29\%, na Itália (Gringoli et al., 1996).

Evidência sorológica de infecção por Neospora em cães, na América do Sul, foi primeiramente descrita por Barber et al. (1997) em cães do Uruguai e nas Ilhas Malvinas, em pesquisa utilizando-se IFI em 1554 soros de três continentes (África, América do Sul e Oceania). Anticorpos para N. caninum foram posteriormente relatados em cães da Argentina (Basso et al., 2001), Brasil (Gennari et al., 2002; Cañón-Franco et al., 2003; Fernandes et al., 2004) e Chile (Patitucci et al., 2001).
No Brasil, a infeção por $N$. caninum em cães foi relatada em Uberlândia-MG (Fernandes et al., 2004), no Paraná (Souza et al., 2002), em São Paulo-SP (Gennari et al., 2002), em JaboticabalSP (Rached et al., 2001) e em Monte Negro-RO (Cañón-Franco et al., 2003). Este é o primeiro registro no estado do Maranhão. Os percentuais de animais soropositivos citados por esses autores variaram, mas foram inferiores aos obtidos neste estudo.

Gennari et al. (2002) observaram soroprevalência de $40,1 \%$ em cães de rua $(25 / 61)$ e de $20 \%$, em cães com domicílio fixo. Cães de áreas periurbanas apresentaram soroprevalência mais alta do que os de áreas urbanas (Fernandes et al., 2004). Os animais com acesso à rua ou contato com outras espécies animais podem ser mais freqüentemente infectados com $N$. caninum (Gennari et al., 2002; Fernandes et al., 2004). Patitucci et al. (2001) observaram diferenças no percentual de cães positivos que comiam carne crua (29,5\%). Também Cañón-Franco et al. (2003) mencionaram que a proporção de cães soropositivos sob dieta caseira foi maior do que a de cães alimentados com comida comercial.

Essas observações poderiam explicar a alta prevalência detectada neste estudo, desse modo, cães de rua poderiam desempenhar importante papel epidemiológico na disseminação de $N$. caninum.

Palavras-chave: cão, freqüência, Neospora caninum, imunoflorescência indireta, Maranhão

\begin{abstract}
The frequency of antibodies to Neospora caninum (Protozoa: Apicomplexa) in dog sera was investigated. Blood samples from 100 mongrel dogs, captured in the streets of São Luis, State of Maranhão, were analized using imunofluorescent antibody test. Forty five percent of the dogs were positive, and the titers ranged from 1:50 to 1:800. No sex difference was observed for frequency of $\mathrm{N}$. caninum $160 \%$ in males and $40 \%$ in females). This is the first report of antibodies to N. caninum in dogs from Maranhão.
\end{abstract}

Keywords: dog, frequency, Neospora caninum, indirect imunofluorescent, Maranhão, Brazil

\section{REFERÊNCIAS BIBLIOGRÁFICAS}

BARBER, J.S.; GASSER, R.B.; ELLIS, J. et al. Prevalence of antibodies to Neospora caninum in different canid populations. J. Parasitol., v.83, p.1056-1058, 1997.
BASSO, W.; VENTURINI, L.; VENTURINI, M.C. et al. Prevalence of Neospora caninum infection in dogs from beef cattle farms, dairy farms, and from urban areas of Argentina. $J$. Parasitol., v.87, p.906-907, 2001. 
BJERKÅS, I.; MOHN, S.F.; PRESTHUS, J. Unidentified cyst-forming sporozoan causing encephalomyelitis and myositis in dogs. $Z$. Parasitenkd, v.70, p.271-274, 1984.

BJÖRKMAN, C.; UGGLA, A. Serological diagnosis of Neospora caninum infection. Int. $J$. Parasitol., v.29, p.1497-1507, 1999.

CAÑÓN-FRANCO, W.A.; BERGAMASCHI, D.P.; LABRUNA, M.B. et al. Prevalence of antibodies to Neospora caninum in dogs from Amazon, Brazil. Vet. Parasitol., v.115, p.71-74, 2003.

DUBEY, J.P.; CARPENTER, J.L.; SPEER, C.A. et al. Newly recognized protozoan disease of dogs. J. Am. Vet. Med. Assoc., v.192, p.12691285,1988

FERNANDES， B.C.T.M.; GENNARI， S.M.; SOUZA, S.L.P. et al. Prevalence of antiNeospora caninum antibodies in dogs from urban, periurban and rural areas of the city of Uberlândia, Minas Gerais, Brazil. Vet. Parasitol., v.123, p.33-40, 2004.

GENNARI, S.M.; YAI, L.E.O.; D’ÁURIA, S.N.R. et al. Occurrence of Neospora caninum antibodies in sera from dogs of the city of São Paulo, Brazil. Vet. Parasitol., v.106, p.177-179, 2002.

GRINGOLI, G.; CAPUANO, F.; VENECIANO, V. Prevalence of antibodies against Neospora caninum in dog sera. Vet. Parasitol., v.38, p.282, 1996.

HAY, W.H.; SHELL, L.G.; LINDSAY, D.S. et al. Diagnosis and treatment of Neospora caninum infection in a dog. J. Am. Vet. Med. Assoc., v.197, p.87-89, 1990.

McALLISTER, M. M.; DUBEY, J.P.; LINDSAY, D.S. et al. Dogs are definitive hosts of Neospora caninum. Int. J. Parasitol., v.28, p.1473-1478, 1998.

PATITUCCI, A.N.; PÉREZ, M.J.; ROZAS, M.A. et al. Neosporosis canine: detection of sera antibodies in rural and urban canine population of Chile. Arch. Med. Vet., v.33, p.227-232, 2001.

RACHED, P.A.; PRETTE-VARANDAS, N.; SILVA, H.C. et al. Freqüência de anticorpos anti-Neospora caninum e anti-Toxoplasma gondii em cães portadores de neuropatias. $J$. Bras. Patol., v.37, p.216, 2001.

SAWADA, M.; PARK, C.H.; KONDO, H. et al. Serological survey of antibody to Neospora caninum in japanese dogs. J. Vet. Med. Sci., v.60, p.853-854, 1998.

SOUZA, S.L.P.; GUIMARÃES, J.S.; FERREIRA, F. et al. Prevalence of Neospora caninum antibodies in dogs from dairy cattle farms in Paraná, Brazil. J. Parasitol., v.88, p.408-409, 2002.

THISLSTED, J.P.; DUBEY, J.P. Neosporosislike abortions in a herd of dairy cattle. J. Vet. Diagn. Invest., v.1, p.205-209, 1989.

TREES, A.J.; GUY, F.; TENNANT, B.J. et al. Prevalence of antibodies to Neospora caninum in population of urban dogs in England. Vet. Rec., v.132, p.125-126, 1993. 